\title{
Toll-like receptor activation by helminths or helminth products to alleviate inflammatory bowel disease
}

\author{
ShuMin Sun ${ }^{1,2 \dagger}$, XueLin Wang ${ }^{1 \dagger}$, XiuPing $\mathrm{Wu}^{1 \dagger}$, Ying Zhao ${ }^{1 *}$, Feng Wang ${ }^{1 *}$, XiaoLei Liu ${ }^{1}$, YanXia Song ${ }^{1}$, \\ ZhiLiang $\mathrm{Wu}^{3}$ and MingYuan Liu ${ }^{1 *}$
}

\begin{abstract}
Helminth infection may modulate the expression of Toll like receptors (TLR) in dendritic cells (DCs) and modify the responsiveness of DCs to TLR ligands. This may regulate aberrant intestinal inflammation in humans with helminthes and may thus help alleviate inflammation associated with human inflammatory bowel disease (IBD). Epidemiological and experimental data provide further evidence that reducing helminth infections increases the incidence rate of such autoimmune diseases. Fine control of inflammation in the TLR pathway is highly desirable for effective host defense. Thus, the use of antagonists of TLR-signaling and agonists of their negative regulators from helminths or helminth products should be considered for the treatment of IBD.
\end{abstract}

Keywords: Toll Like Receptors, Helminth, Inflammatory Bowel Disease

\section{Background}

Crohn's disease (CD) and ulcerative colitis (UC) are two forms of inflammatory bowel disease (IBD) that are autoimmune-like disorders characterized by chronic, idiopathic inflammation of the intestinal mucosal tissue, which causes a range of symptoms including abdominal pain, severe diarrhoea, rectal bleeding and wasting [1,2]. Patients with UC and CD are at increased risk of developing colorectal cancer. Chronic inflammation is believed to promote carcinogenesis [3].

$\mathrm{CD}$ and $\mathrm{UC}$ are distinguished by the tissues affected: $\mathrm{CD}$ can affect any region of the gastrointestinal tract in a discontinuous and transmural manner, whereas pathology in UC is restricted to the surface mucosa of the colon, in particular the rectum [4]. Current treatment regimens, including anti-inflammatory and immunosuppressive agents, are not curative and only reduce

\footnotetext{
* Correspondence: zhaoyingsohu@sohu.com; wangfengcn@yahoo.com.cn; liumy@jlu.edu.cn

† Contributed equally

'Key Laboratory of Zoonosis Research, Ministry of Education, Institute of Zoonosis, Jilin University; Zoonosis Research Centre of State Key Laboratory for Molecular Virology and Genetic Engineering, Institute of Pathogen Biology, Chinese Academy of Medical Sciences, Changchun 130062, People's Republic of China

Full list of author information is available at the end of the article
}

the degree of intestinal inflammation associated with disease [5].

Genetic studies have provided new evidence to suggest that derangements in innate and adaptive immunity result in human IBD [2]. In 1989, the "hygiene hypothesis" was proposed by D.P. Strachan in an article that claimed an inverse relationship between the occurrence of hay fever and numbers of siblings [6]. According to the hypothesis, atopic disorders are due to reduced exposure to microorganisms in childhood [7]. IBD tends to emerge in childhood, occurs primarily in immunocompetent individuals and is most prevalent in westernized regions of the world [8]. Weinstock [9] proposed that the modern lifestyle lacking consistent exposure to intestinal helminths is an important environmental factor contributing to IBD. Cross-sectional studies on the relationship between skin prick tests and helminth infections suggested a general protective effect on the atopic reaction [10]. Nowadays, the concept is becoming more accepted, with accumulating evidence not only in atopic diseases but also in autoimmune inflammatory diseases [11]. Many studies have since demonstrated that helminth infections lower the risk of autoimmunity or allergy [12]. Thus, parasitic worms are important for shaping, or tuning, the development and the function of 
the immune systems of human beings. Helminths (nematodes, cestodes and trematodes) have been used in ameliorating chemically induced colitis in different models $[13,14]$.

Khan et al supported these results by infecting mice with Trichinella spiralis and showed that mice were protected from colitis induced by an intrarectal challenge using dinitrobenzene sulfate (DNBS) [15]. Reardon et al. evidenced that mice infected with the tapeworm Hymenolepis diminuta, ameliorated dextran sodium sulfate (DSS)-induced colitis [16]. Helminths can attenuate experimentally induced IBD in animal models $[17,18]$, but the work of Summers et al. also shows promise in that natural exposure to helminths, such as T. suis, affords protection from immunological diseases like CD $[19,20]$. Epidemiological and experimental data strongly support the hypothesis that a reduction in helminth infection is linked to a rise in the incidence rates of autoimmune diseases [21].

\section{Basic immunopathology of IBD}

An important role for TLR signaling in the pathogenesis of IBD has been established through many studies over the last decade [22-24]. In the IBD-susceptible host, aberrant TLR signaling may contribute to destructive host responses and chronic inflammation, disturbing mucosal and commensal homeostasis and leading to many different clinical phenotypes [25]. Hyperactivation of the adaptive immune system, secondary to TLR deficiency, may drive tissue damage and progressive inflammation in IBD [26,27]. Characterization of different IBD-associated gene defects have highlighted fundamental, defining variability in TLR regulation and function, dependent on disease processes and predominant cell type involvement in the intestinal mucosa $[28,29]$. TLRs and pattern recognition receptors (PRRs) may be central to future progress in identifying novel approaches that may exploit innate immune functions as a means to prevent and/or treat IBD and related systemic manifestations.

It is now clear that the innate immune system comprised of TLRs and related molecules, plays a key role in the regulation of intestinal inflammation and in the recognition of invading pathogens [30]. TLRs comprise the major innate immune surveillance, recognition and response receptors central to efficient host defense and homeostasis of the intestinal mucosa [31,32]. There are currently 11 known mammalian TLRs. They are transmembrane receptors that are found either on the cell membrane (TLR1, 2, 4, 5 and 9) or on intracellular organelles (TLR3, 7 and 8) [33]. TLRs are expressed throughout the gastrointestinal (GI) tract on intestinal epithelial cells (IECs), myofibroblasts, enteroendocrine cells, and on immune cells within the lamina propria, such as T cells, and dendritic cells (DCs) [34-38]. Ligand binding to TLRs initiates signaling cascades that activate $\mathrm{NF}-\kappa \mathrm{B}, \mathrm{MAPK}$, and interferon response factors [39].

TLR molecules and their downstream signaling pathways play a crucial role in selected cell types in adaptive immunity and in activating innate immune cells of the immune system $[40,41]$. Given that this pathway is aberrantly expressed or activated in several diseases, it constitutes a potential target for therapeutic intervention. There is mounting evidence documenting that the interruption of this pathway at the level of TLR, myeloid differentiation factor-88 (MyD88), or IL-I receptorassociated kinase (IRAK) will improve therapeutic efficacy in autoimmunity and auto-inflammatory diseases [42-44]. On the contrary, the total abolition of these pathways may compromise the immune defense against invading infections and immune surveillance $[45,46]$. Actually, agonists of these pathways appear to be useful in IBD development. Hence, there is a need to mindfully select the therapeutic target in the TLR signaling cascade and closely regulate the degree of pathway activity so as to procure the ideal therapeutic end point [47].

In the intestine, the end result of TLR signaling is the activation of nuclear factor kappa-B (NF- $\kappa \mathrm{B})$, triggering off the induction of pro-inflammatory cytokines or interferon (IFN) response factors (IRFs), depending on the induction of type I interferons (Figure 1). TLRdependent activation of NF- $\kappa$ B plays an important role in sustaining epithelial homeostasis as well as in regulating infections and inflammation, while the dysregulation of TLR-signaling is associated with the pathogenesis of IBD $[48,49]$. Recent findings on innate immunitymediated regulation of intestinal pathophysiology prove that the development of new drugs targeting TLRs, including antagonists of TLR-signaling and agonists of their negative regulators, hold promise for new therapeutic strategies for intestinal inflammatory diseases [50].

\section{Helminth infection affects key aspects of gut inflammatory biology}

Negative regulation of TLRs reduces pro-inflammatory cytokine production, protecting the host from autoimmune pathogenesis [51]. Helminths can both activate and negatively regulate TLRs, which suggests that the immune response to these infective helminths is under tight control [52]. Zhao et al. [53] reported that Schistosoma japonicum eggs could alleviate TNBS-induced colitis in mice. The mechanism for this action was assumed to be due to the regulation of T-helper cell $1 / 2$ balance and TLR4 expression. In brief, these reports make a significant contribution in that helminths will execute positive therapy in IBD by targeting the TLR signaling pathway. 


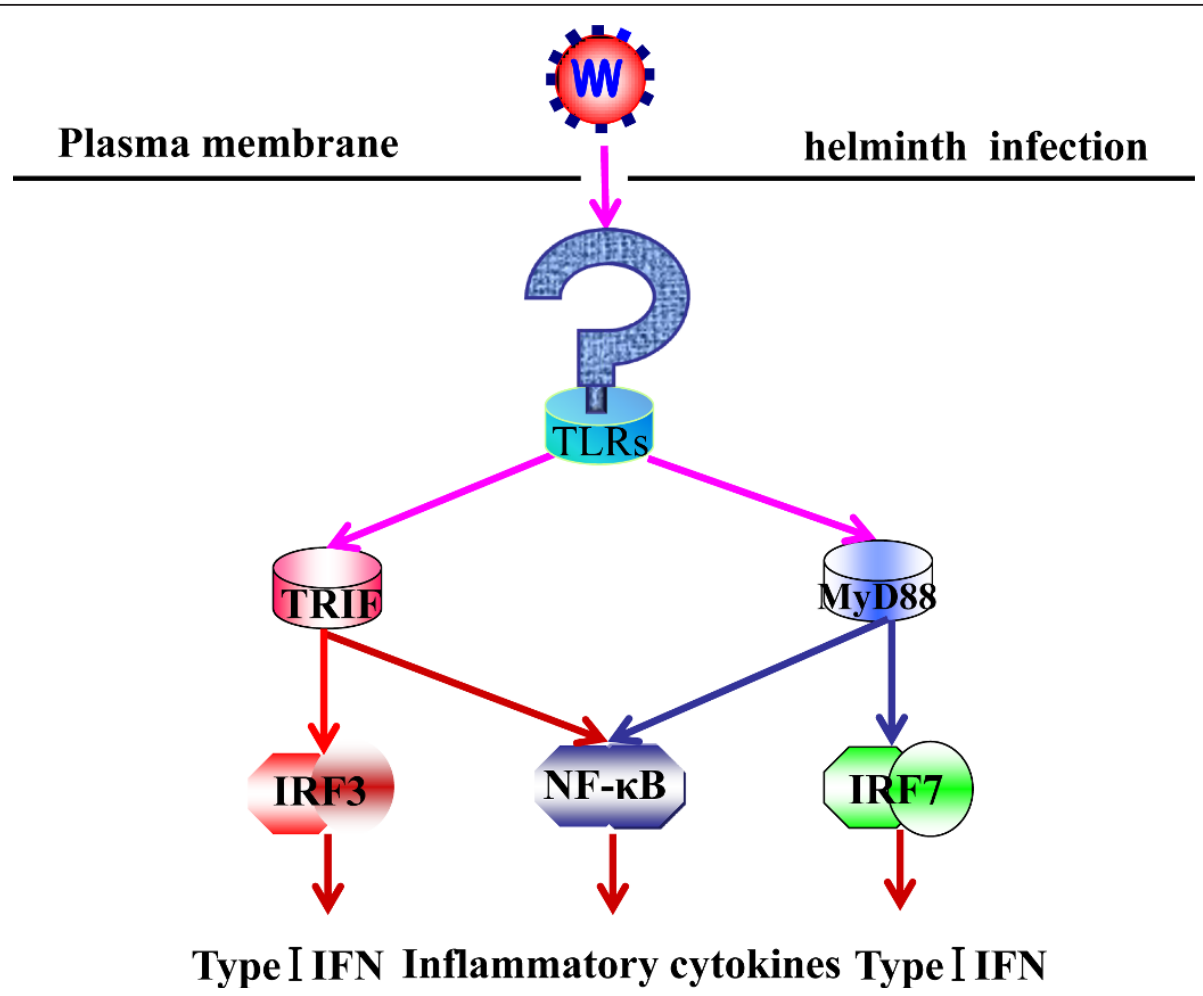

Figure 1 TLR induction of inflammation by parasitic infection. MyD88, TLRs and toll/IL-1 receptor domain-containing adaptor protein inducing interferon (TRIF) signal transduction is activated by helminth infection, which results in the activation of NF- $\kappa$ B, IRF7 and IRF3 for the induction of type I interferons (TRIF-dependent pathway). Activation of NF- $\kappa \mathrm{B}$ is required for the induction of inflammatory cytokines.

The critical roles of TLRs are to sustain the integrity of the epithelial barrier and to accelerate maturation of the mucosal immune system. Mice deficient in TLRs can develop intestinal inflammation [54]. IECs express TLRs that recognize specific molecular signatures of helminths, which can then trigger intracellular signaling pathways inducing the production of pro-inflammatory cytokines and chemokines (Figure 2). TLR responses are tightly regulated in order to induce protective responses while reducing excessive and detrimental inflammatory responses for IEC $[55,56]$.

Recent studies have demonstrated that TLR signals can influence intestinal homeostasis [57]. One study proved that the expression levels of TLR-2, TLR-4, TLR-9 and TLR-11 were significantly raised in mouse IECs following infection with Toxoplasma gondii on day 8 post-infection [58]. Mucosal cells and consequent activation of signaling cascades including activator protein 1 (AP1), mitogenactivated protein kinases, NF- $\kappa \mathrm{B}$ and IRFs can enhance the production of pro-inflammatory cytokines and antimicrobial peptides, as well as the maintenance of the epithelial barrier function and epithelial cell proliferation [59]. Hence, parasitic infection can maintain the epithelial barrier function and epithelial cell proliferation through TLR signaling pathways [60].
Intestinal parasitic infections also activate mucin hypersecretion, which is a key response of the innate immune system for intestinal homeostasis [61]. One study suggests that Gymnophalloides seoi antigen can induce mucinrelated 2 (MUC2) expression by the activation of the TLR pathways in human IECs [62]. The expression and regulation of MUC genes were reported in rodents infected with intestinal nematodes, including Trichinella spiralis and Nippostrongylus brasiliensis [63]. These results suggest the possibility that the expression of the MUC2 gene may be closely associated with TLR pathways $[64,65]$. Consequently, helminthes, or their products, may promote the physical barrier function of IECs by TLR activation.

Thus, the fine control of inflammation by helminths in the TLR pathway is highly feasible for effective host defense via TLR-dependent pro-inflammatory cascades triggered by parasitic infections, which must be tightly regulated to avoid severe pathology or even mortality in IBD patients [51].

\section{Bioactive helminths or helminth products}

TLRs trigger an intracellular signaling cascade through the toll/IL-1 receptor (TIR) [66] and through the recruitment of adaptor molecules, such as TIR domaincontaining adaptor molecule-1 (TICAM-1), MyD88 and 


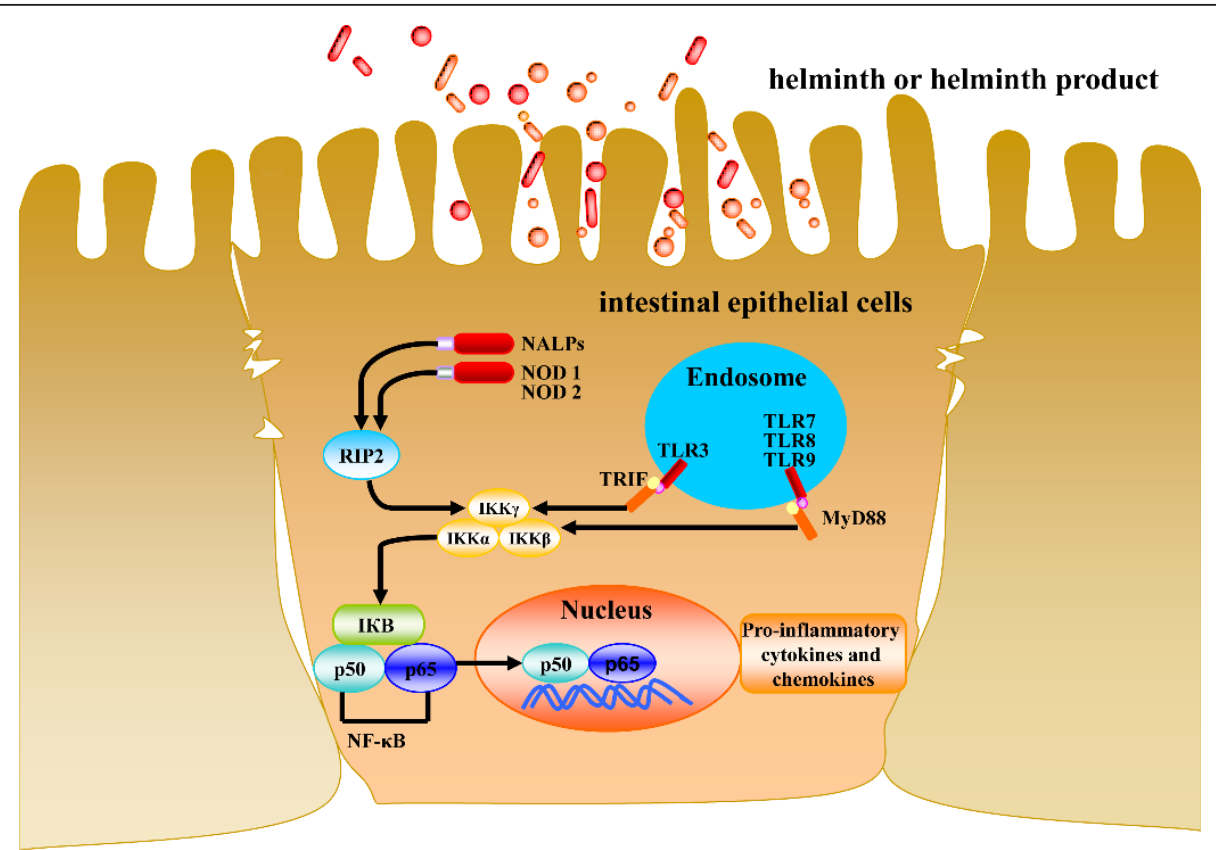

Figure 2 Contribution of TLRs to mucous membrane immunity. Pattern-recognition receptors, including toll-like receptors (TLRs) and nucleotide-binding oligomerization domain- (NOD)-like receptors (NLRs), are expressed by most IEC. TLR ligation leads to the recruitment of adaptor proteins, such as TIR domain-containing adaptor protein inducing interferon (TRIF), MyD88 (myeloid differentiation primary-response gene 88 ) and subsequent activation of several signaling modules, including mitogen-activated protein (MAP) kinase pathways NF- $\kappa$ B. Activation of PRRs by helminth infection advances a cascade of signaling events that results in the expression of pro-inflammatory cytokines and chemokines.

TRIF, and TRIF-related adaptor molecule (TRAM) $[67,68]$. These adaptor molecules act independently, or in combination, based on the TLRs and trigger NF- $\kappa \mathrm{B}$, c-Jun-N-terminal kinase (JNK), mitogen-activated protein kinases (MAPK), p38, extracellular signal-regulated kinase (ERK) and NF- $\kappa$ B leading to the transcription of inflammatory and immunomodulatory genes including co-stimulatory molecules, cytokines and chemokines $[69,70]$ (Figure 3). In IBD therapy by helminths or helminth products, negative regulation of TLR signaling is critical for the down regulation of gene activation in controlling overwhelming inflammation and pro-inflammatory cytokine production.

A recent report indicates that helminth infection may alter TLR4 expression in mucosal T cells [37]. Schistosoma derived lysophosphatidyl-serine contains a helminth-specific acyl chain that, through influence on TLR2, promotes the differentiation of DCs that induce regulatory $\mathrm{T}$ cells, which secrete the anti-inflammatory cytokine interleukin-10 (IL-10) [71]. Studies conducted by Meyer et al. [72] suggest that the soluble fractions from Schistosoma mansoni eggs may alter TLR ligandinduced activation of DCs. The broad effect of excretory-secretory products (ESP) of Fasciola hepatica on different TLR signaling regulation could be an immediate action of these antigens (Ags) on TLR expression.
Falcón demonstrated that ESP was also able to affect the MyD88-dependent signaling pathway [73]. These results indicate that different helminths may modulate the TLR expression of DCs and responsiveness of DCs to TLR ligands and finally stimulate cell-mediated immunity (Figure 4). Nevertheless, characterization of the signals induced by these immunomodulators suggest overturn of the normal TLR-induced MAPK and that NF- $\kappa B$ pathways lead to antigen presentation of an immature phenotype to antigen-presenting cells (APCs) that subsequently reduce levels of proinflammatory cytokines [74,75]. Logically, the biological characteristics of helminths should be considered for IBD therapy.

\section{Ameliorating the inflammation strategy}

The intestinal tract is the largest and most complex immune environment in the human body. Successful therapy for these tissues will require accurate timing and targeting the optimal location. The number of therapeutics being developed for IBD has increased dramatically over the last 2 decades because of rapid gains in our understanding of the mechanisms of inflammation [76].

Disturbing TLR signaling by helminths or helminth products is expected to be a promising strategy in IBD treatment because TLR signaling can inhibit 


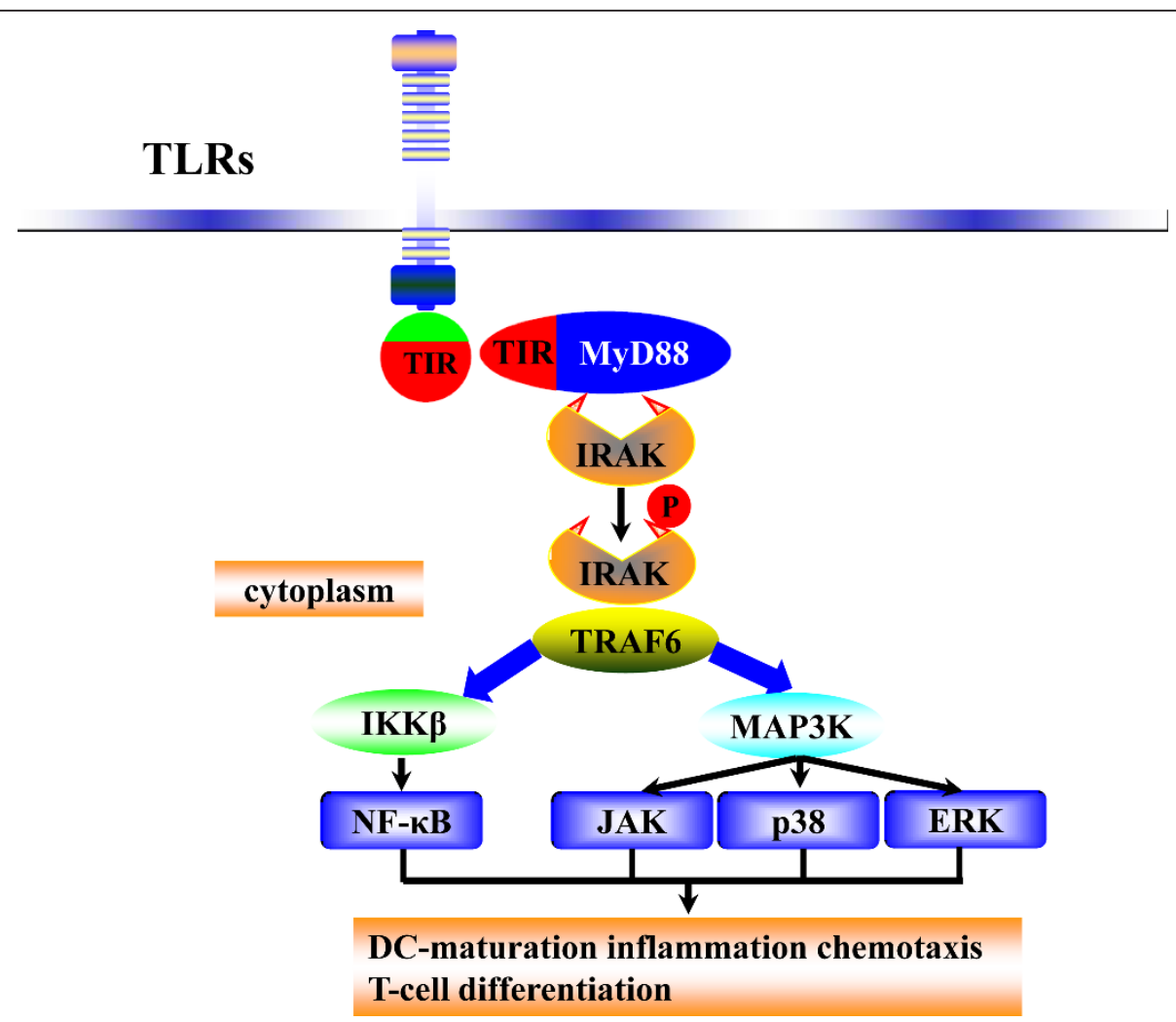

Figure 3 TLR regulation of pro-inflammatory cytokines. Activation of toll-like receptors and type I IL-1 receptors evoke inflammation in immune cells by sharing signaling cascades. TLRs expressed on professional immune cells (macrophages, dendritic, monocytes and microglia cells) discern and respond to helminth infection. TLRs are triggered by helminth or helminth products containing pathogen-associated molecular patterns (PAMPs). All TLR family members and the type I interleukin-1 receptor (IL-1RI) have specific intracellular TIR signaling domains. In response to activation by the corresponding ligands, TIR domains react with the TIR domains of the signaling adaptor MyD88, which convey the signal to a family of IL-1 receptor-associated kinases (IRAKs). Phosphorylation of IRAK, a serine-threonine kinase, by other IRAK family members provoke cascades of signaling through tumor necrosis factor receptor-associated factor 6 (TRAF6). TRAF6 relays a signal to I kappa B kinase (IKK) and to mitogen-activated protein kinase kinase (MAP3K). This signaling leads to transcriptional responses, mediated primarily by ERK, NF- $\kappa B$ and stress-activated protein kinases, for example JNK and p38, result in the expression of pro-inflammatory cytokines.

inflammatory responses in innate immune cells [77]. van Stijn et al. [78] demonstrate that TLR4 activation by worm glycolipids may elicit Th1 immune responses in Schistosoma infection. Donnelly et al. [79] showed that parasite proteases specifically degrade TLR3 within the endosome, which reduces macrophage activation in response to both TLR3 and TLR4 stimulation. Maintaining the epithelial barrier function and IEC proliferation by TLR signals[80] is another strategy of IBD therapy by the parasite or products derived from the parasite. In report of Lee et al [65], the intestinal trematode G. seoi was employed in inducing the expression of TLR4, TLR2 and the MUC2 gene in a human IEC. MUC2 has been used in alleviating ulcerative colitis of the IBD model mouse [81].

Cysteine proteases, excretory-secretory (ES) production and antigens from helminths with potential TLR ligands that may obtain more effective agonists or antagonists of a targeted function of TLRs signaling need to be considered in IBD treatment. One study showed that the major cysteine proteases secreted from $F$. hepatica and S. mansoni specifically disturb the MyD88-independent, TRIF-dependent signaling pathways of TLR4 and TLR3 for the modulation of the innate immune responses of their hosts [79]. These results clearly show the benefits of local treatment with helminth antigens for experimental colitis and prompt consideration of helminth antigen-based therapy for IBD, in lieu of infection with live parasites.

\section{Conclusions}

Epidemiological, experimental and clinical data support the idea that helminths could provide protection against IBD. Correale and Farez [82] evidenced that a soluble egg Ag (SEA) obtained from Schistosoma mansoni exerts potent regulatory effects on both DCs and B cells through TLR2 regulation in patients with the autoimmune disease, multiple sclerosis. Summers et al. [19] demonstrated that 




Figure 4 Adaptive T-cell immune response induced by TLRS. Mammalian toll-like receptors are expressed on all kinds of immune cells, including dendritic cells and monocytes. Activation of toll-like receptors induces signaling pathways that activate the transcription factor NF-B, leading to the transcription of genes that modulate and mediate immune responses. Activation of these pathways results in the release of proinflammatory cytokines, which affects the adaptive T-cell immune response.

it is safe to administer eggs from the porcine whipworm, Trichuris suis, to patients with CD and UC. The study suggests that it is possible to down-regulate aberrant intestinal inflammation in humans with helminthes. Local treatment using antagonists of TLR-signaling and agonists of their negative regulators from helminthes or helminth products ought to prompt consideration for treatment of IBD instead of infection with live parasites.

\section{List of abbreviations}

IBD: inflammatory bowel disease; DCs: dendritic cells; Treg: regulatory T cell; TLR: Toll-like receptor; CD: Crohn's disease; UC: ulcerative colitis; DNBS: dinitrobenzene sulfate; DSS: dextran sodium sulfate; PRRs: pattern recognition receptors; GI: gastrointestinal; IECs: intestinal epithelial cells; MyD88: myeloid differentiation factor-88; IRAK: IL-I receptor-associated kinase; NF-KB: nuclear factor kappa-B; IFN: interferon; IRFs: interferon response factors; TRIF: toll/LL-1 receptor domain-containing adaptor protein inducing interferon; TIR: toll/IL-1 receptor; NOD: nucleotide-binding oligomerization domain; NLRs: nucleotide-binding oligomerization domain-like receptors; NALPs: neutrophilic alkaline phosphatases; RIP: regulated intramembrane proteolysis; MAP: mitogen-activated protein; AP1: activator protein 1; MUC2 mucin-related 2; TICAM-1: TIR domain-containing adapter molecule-1; TIRAP: TIR domain-containing adaptor protein; TRAM: TRIF-related adaptor molecule; JNK: c-Jun-N-terminal kinase; MAPK: mitogen-activated protein kinases; ERK: extracellular signal-regulated kinase; PAMPs: pathogenassociated molecular patterns; IL-1RI: type I interleukin-1 receptor; IRAKs: IL-1 receptor-associated kinases; TRAF6: tumor necrosis factor receptor-associated factor 6; IKK: I kappa B kinase; ESP: excretory-secretory products; APCs: antigen-presenting cells; ES: excretory-secretory; SEA: soluble egg Ag.

\section{Acknowledgements}

The work was supported by the National S \& T Major Program (No. 2008ZX10004-11), the MOST 2010 CB530000 and 2011AA10A200, and the National Natural Science Foundation of China (NSFC: 30825033, 31030064, $30972177,81070311,31072124)$ and was supported by the Graduate Innovation Fund of Jilin University (No: 20101058). Professor Benjamin M. Rosenthal at The Animal Parasitic Diseases Laboratory, Agricultural Research Service, United States Department of Agriculture is gratefully thanked for editing the manuscript in grammar and writing style.

\section{Author details}

'Key Laboratory of Zoonosis Research, Ministry of Education, Institute of Zoonosis, Jilin University; Zoonosis Research Centre of State Key Laboratory for Molecular Virology and Genetic Engineering, Institute of Pathogen Biology, Chinese Academy of Medical Sciences, Changchun 130062, People's Republic of China. ${ }^{2}$ Animal Science and Technology College, Inner Mongolia University for Nationalities, 028000 Tongliao, People's Republic of China. ${ }^{3}$ Department of Parasitology, Gifu University Graduate School of Medicine, Yanagido 1-1, Gifu 501-1194, Japan.

\section{Authors' contributions}

SMS, ZLW and MYL drafted the manuscript. XLW, XPW, YZ, FW, XLL and YXS collected material or generalized useful information from the collected material in the paper. All authors approved the final version of the manuscript.

\section{Competing interests}

The authors declare that they have no competing interests. 
Received: 9 April 2011 Accepted: 27 September 2011

Published: 27 September 2011

\section{References}

1. Himmel ME, Hardenberg G, Piccirillo CA, Steiner TS, Levings MK: The role of T-regulatory cells and Toll-like receptors in the pathogenesis of human inflammatory bowel disease. Immunology 2008, 125:145-153.

2. Rakoff-Nahoum S, Bousvaros A: Innate and adaptive immune connections in inflammatory bowel diseases. Curr Opin Gastroenterol 2010, 26:572-577.

3. Ullman TA, Itzkowitz SH: Intestinal inflammation and cancer. Gastroenterology 2011, 140:1807-1816.

4. Cho JH: The genetics and immunopathogenesis of inflammatory bowel disease. Nat Rev Immunol 2008, 8:458-466.

5. Loftus EV Jr: Clinical epidemiology of inflammatory bowel disease: Incidence, prevalence, and environmental influences. Gastroenterology 2004, 126:1504-1517.

6. Strachan DP: Hay fever, hygiene, and household size. BMJ 1989, 299:1259-1260.

7. Okada H, Kuhn C, Feillet H, Bach JF: The 'hygiene hypothesis' for autoimmune and allergic diseases: an update. Clin Exp Immunol 2010, 160:1-9.

8. Strober W, Fuss I, Mannon P: The fundamental basis of inflammatory bowel disease. J Clin Invest 2007, 117:514-521.

9. Weinstock JV, Elliott DE: Helminths and the IBD hygiene hypothesis. Inflamm Bowel Dis 2009, 15:128-133.

10. Flohr C, Quinnell RJ, Britton J: Do helminth parasites protect against atopy and allergic disease? Clin Exp Allergy 2009, 39:20-32.

11. Aoyama H, Hirata T, Sakugawa H, Watanabe T, Miyagi S, Maeshiro T, Chinen T, Kawane M, Zaha O, Nakayoshi T, Kinjo F, Fujita J: An inverse relationship between autoimmune liver diseases and Strongyloides stercoralis infection. Am J Trop Med Hyg 2007, 76:972-976.

12. Osada $Y$, Kanazawa T: Parasitic helminths: new weapons against immunological disorders. J Biomed Biotechnol 2010, 2010:743-758.

13. Bruschi F, Chiumiento L: Trichinella inflammatory myopathy: host or parasite strategy? Parasit Vectors 2011, 4:42.

14. Harnett W, Harnett MM: Therapeutic immunomodulators from nematode parasites. Expert Rev Mol Med 2008, 19:10-23.

15. Khan WI, Blennerhasset PA, Varghese AK, Chowdhury SK: Intestinal nematode infection ameliorates experimental colitis in mice. Infect Immun 2002, 70:5931-5937.

16. Reardon C, Sanchez A, Hogaboam CM, MCKay DM: Tapeworm infection reduces epithelial ion transport abnormalities in murine dextran sulfate sodium-induced colitis. Infect Immun 2001, 69:4417-4423.

17. Ruyssers NE, De Winter BY, De Man JG, Loukas A, Pearson MS, Weinstock JV: Therapeutic potential of helminthes soluble proteins in TNBS-induced colitis in mice. Inflamm Bowel Dis 2009, 15:491-500.

18. Elliott DE, Summers RW, Weinstock JV: Helminths as governors of immune-mediated inflammation. Int J Parasitol 2007, 37:457-464.

19. Summers RW, Elliott DE, Urban JF Jr, Thompson R, Weinstock JV: Trichuris suis therapy in Crohn's disease. Gut 2005, 54:87-90.

20. Summers RW, Elliott DE, Qadir K, Urban JF Jr, Thompson R, Weinstock JV: Trichuris suis seems to be safe and possibly effective in the treatment of inflammatory bowel disease. Am J Gastroenterol 2003, 98:2034-2041.

21. Rook GA: Review series on helminths, immune modulation and the hygiene hypothesis: the broader implications of the hygiene hypothesis. Immunology 2009, 126:3-11.

22. Wei J, Feng J: Signaling pathways associated with inflammatory bowel disease. Recent Pat Inflamm Allergy Drug Discov 2010, 4:105-17.

23. Vavricka SR, Rogler G: New insights into the pathogenesis of Crohn's disease: are they relevant for therapeutic options? Swiss Med Wkly 2009, 139:527-534

24. Sepúlveda SE, Beltrán CJ, Peralta A, Rivas P, Rojas N, Figueroa C, Quera R, Hermoso MA: Inflammatory bowel diseases: an immunological approach. Rev Med Chil 2008, 136:367-75.

25. Cario E: Toll-like receptors in inflammatory bowel diseases: a decade later. Inflamm Bowel Dis 2010, 16:1583-1597.

26. Nikoopour E, Schwartz JA, Singh B: Therapeutic benefits of regulating inflammation in autoimmunity. Inflamm Allergy Drug Targets 2008, 7:203-210

27. Sartor RB, Muehlbauer M: Microbial host interactions in IBD: implications for pathogenesis and therapy. Curr Gastroenterol Rep 2007, 9:497-507.
28. Cario E: Therapeutic impact of toll-like receptors on inflammatory bowel diseases: a multiple-edged sword. Inflamm Bowel Dis 2008, 14:411-421.

29. Ishihara S, Rumi MA, Ortega-Cava CF, Kazumori H, Kadowaki Y, Ishimura N, Kinoshita $Y$ : Therapeutic targeting of toll-like receptors in gastrointestinal inflammation. Curr Pharm Des 2006, 12:4215-4228.

30. Takeda K, Akira S: Toll-like receptors in innate immunity. Int Immunol 2005, 17:1-14.

31. Mowat AM: Does TLR2 regulate intestinal inflammation? Eur I Immunol 2010, 40:318-320.

32. Zeytun A, Chaudhary A, Pardington P, Cary R, Gupta G: Induction of cytokines and chemokines by Toll-like receptor signaling: strategies for control of inflammation. Crit Rev Immunol 2010, 30:53-67.

33. Zhang D, Zhang G, Hayden MS, Greenblatt MB, Bussey C, Flavell RA, Ghosh S: A toll-like receptor that prevents infection by uropathogenic bacteria. Science 2004, 303:1522-1526.

34. Cario E, Rosenberg IM, Brandwein SL, Beck PL, Reinecker HC, Podolsky DK Lipopolysaccharide activates distinct signaling pathways in intestinal epithelial cell lines expressing Toll-like receptors. J Immunol 2000, 164:966-972.

35. Otte JM, Rosenberg IM, Podolsky DK: Intestinal myofibroblasts in innate immune responses of the intestine. Gastroenterology 2003, 124:1866-1878.

36. Baumgart DC, Buning C, Geerdts L, Schmidt HH, Genschel J, Fiedler T, Gentz E, Molnar T, Nagy F, Lonovics J, Lochs H, Wiedenmann B, Nickel R, Witt H, Dignass A: The C.1-260C > T promoter variant of CD14 but not the c.896A > G (p.D299G) variant of toll-like receptor 4 (TLR4) genes is associated with inflammatory bowel disease. Digestio 2007, 76:196-202.

37. Ince $M N$, Elliott $D E$, Setiawan $T$, Blum A, Metwali A, Wang $Y$, Urban JF Jr, Weinstock JV: Heligmosomoides polygyrus induces TLR4 on murine mucosal T cells that produce TGFbeta after lipopolysaccharide stimulation. J Immunol 2006, 176:726-729.

38. Hart AL, Al-Hassi HO, Rigby RJ, Bell SJ, Emmanuel AV, Knight SC, Kamm MA, Stagg AJ: Characteristics of intestinal dendritic cells in inflammatory bowel diseases. Gastroenterology 2005, 129:50-65.

39. Levin A, Shibolet O: Toll-like receptors in inflammatory bowel diseasestepping into uncharted territory. World I Gastroenterol 2008, 14:5149-153.

40. Kawai T, Akira S: Toll-like receptors and their crosstalk with other innate receptors in infection and immunity. Immunity 2011, 34:637-650.

41. Takeda K: Pathogen recognition through natural immunity. Nihon Jibiinkoka Gakkai Kaiho 2011, 114:1-6.

42. Sadanaga A, Nakashima H, Akahoshi M, Masutani K, Miyake K, Igawa T, Sugiyama N, Niro H, Harada M: Protection against autoimmune nephritis in MyD88-deficient MRL/lpr mice. Arthritis Rheum 2007, 56:1618-1628.

43. Su SB, Silver PB, Grajewski RS, Agarwal RK, Tang J, Chan CC, Caspi RR: Essential role of the MyD88 pathway, but nonessential roles of TLRs 2, 4, and 9 , in the adjuvant effect promoting Th1-mediated autoimmunity. J Immunol 2005, 175:6303-6310.

44. Adachi O, Kawai T, Takeda K, Matsumoto M, Tsutsui H, Sakagami M, Nakanishi K, Akira S: Targeted disruption of the MyD88 gene results in loss of IL-1- and IL-18-mediated function. Immunity 1998, 9:143-150.

45. Barrat FJ, Meeker T, Chan JH, Guiducci C, Coffman RL: Treatment of lupusprone mice with a dual inhibitor of TLR7 and TLR9 leads to reduction of autoantibody production and amelioration of disease symptoms. Eur J Immunol 2007, 37:3582-3586.

46. Pawar RD, Ramanjaneyulu A, Kulkarni OP, Lech M, Segerer S, Anders HJ: Inhibition of Toll-like receptor-7 (TLR-7) or TLR-7 plus TLR-9 attenuates glomerulonephritis and lung injury in experimental lupus. J Am Soc Nephro 2007, 18:1721-1731.

47. Zhu J, Mohan C: Toll-like receptor signaling pathways-therapeutic opportunities. Mediators Inflamm 2010, 781235:1-7.

48. Choi YJ, Im E, Chung HK, Pothoulakis C, Rhee SH: TRIF mediates Toll-like receptor 5-induced signaling in intestinal epithelial cells. J Biol Chem 2010, 285:37570-37578.

49. Ng MT, Van't Hof R, Crockett JC, Hope ME, Berry S, Thomson J, McLean MH, McColl KE, El-Omar EM, Hold GL: Increase in NF-kappaB binding affinity of the variant $C$ allele of the toll-like receptor $9-1237 T / C$ polymorphism is associated with Helicobacter pylori-induced gastric disease. Infect Immun 2010, 78:1345-1352.

50. Johnston KL, Wu B, Guimarães A, Ford L, Slatko BE, Taylor MJ: Lipoprotein biosynthesis as a target for anti-Wolbachia treatment of filarial nematodes. Parasit Vectors 2010, 3:99. 
51. Venugopal PG, Nutman TB, Semnani RT: Activation and regulation of tolllike receptors (TLRs) by helminth parasites. Immunol Res 2009, 43:252-263.

52. Babu S, Blauvelt CP, Kumaraswami V, Nutman TB: Diminished expression and function of TLR in lymphatic filariasis: a novel mechanism of immune dysregulation. J Immunol 2005, 175:1170-1176.

53. Zhao Y, Zhang S, Jiang L, Jiang J, Liu H: Preventive effects of Schistosoma japonicum ova on trinitrobenzenesulfonic acid-induced colitis and bacterial translocation in mice. J Gastroenterol Hepatol 2009, 24:1775-1780.

54. Niev ID, Spadoni I, Mileti E, Matteoli G: Human intestinal epithelial cells promote the differentiation of tolerogenic dendritic cells. Gut 2009, 58:1481--1489.

55. Li YY, Ishihara S, Aziz MM, Oka A: Autophagy is required for toll-like receptor-mediated interleukin-8 production in intestinal epithelial cells. Int J Mol Med 2011, 27:337-344.

56. Bäckhed F, Hornef M: Toll-like receptor 4-mediated signaling by epithelial surfaces: necessity or threat? Microbes Infect 2003, 5:951-959.

57. Fukata M, Abreu MT: Pathogen recognition receptors, cancer and inflammation in the gut. Curr Opin Pharmacol 2009, 9:680-687.

58. Gopal R, Birdsell D, Monroy FP: Regulation of toll-like receptors in intestinal epithelial cells by stress and Toxoplasma gondii infection. Parasite Immunol 2008, 30:563-576.

59. Hooper LV, Wong MH, Thelin A, Hansson L, Falk PG, Gordon Jl: Molecular analysis of commensal host-microbial relationships in the intestine. Science 2001, 291:881-884.

60. Yamamoto M, Takeda K: Current views of toll-like receptor signaling pathways. Gastroenterol Res Pract 2010, 240365:1-8.

61. Moncada DM, Kammanadiminti SJ, Chadee K: Mucin and Toll-like receptors in host defense against intestinal parasites. Trends Parasitol 2003, 19:305-311.

62. Nishigami T, Kataoka TR, Ikeuchi H, Torii I, Sato A, Tomita N, Tsujimura T: Adenocarcinomas associated with perianal fistulae in Crohn's disease have a rectal, not an anal, immunophenotype. Pathology 2011, 43:36-39.

63. Yamauchi J, Kawai Y, Yamada M, Uchikawa R, Tegoshi T, Arizono N: Altered expression of goblet cell- and mucin glycosylation-related genes in the intestinal epithelium during infection with the nematode Nippostrongylus brasiliensis in rat. APMIS 2006, 114:270-278.

64. Cario E, Gerken G, Podolsky DK: Toll-like receptor 2 enhances ZO-1associated intestinal epithelial barrier integrity via protein kinase $C$. Gastroenterology 2004, 127:224-238.

65. Lee KD, Guk SM, Chai JY: Toll-like receptor 2 and Muc2 expression on human intestinal epithelial cells by Gymnophalloides seoi adult antigen. J Parasitol 2010, 96:58-66.

66. Mustelin T: Restless T cells sniff and go. Science 2006, 313:1902-1903.

67. Nagpal K, Plantinga TS, Sirois CM, Monks BG, Latz E, Netea MG, Golenbock DT: Natural loss-of-function mutation of myeloid differentiation protein 88 disrupts its ability to form Myddosomes. J Biol Chem 2011, 286:11875-11882.

68. Kenny EF, O'Neill LA: Signalling adaptors used by Toll-like receptors: an update. Cytokine 2008, 43:342-349.

69. Manna P, Ghosh M, Ghosh J, Das J, Sil PC: Contribution of nano-copper particles to in vivo liver dysfunction and cellular damage: Role of $\mid \mathrm{KBa} /$ NF-kB, MAPKs and mitochondrial signal. Nanotoxicology 2011, 552124:1-21.

70. O'Neill LA, Fitzgerald KA, Bowie AG: The Toll-IL-1 receptor adaptor family grows to five members. Trends Immunol 2003, 24:286-290.

71. Moreels TG, Nieuwendijk RJ, De Man JG, De Winter BY, Herman AG, Van Marck EA: Concurrent infection with Schistosoma mansoni attenuates inflammation induced changes in colonic morphology, cytokine levels, and smooth muscle contractility of trinitrobenzene sulphonic acid induced colitis in rats. Gut 2004, 53:99-107.

72. Meyer S, van Liempt E, Imberty A, van Kooyk Y, Geyer H, Geyer R, van Die I: DC-SIGN mediates binding of dendritic cells to authentic pseudo-LewisY glycolipids of Schistosoma mansoni cercariae, the first parasite-specific ligand of DC-SIGN. J Biol Chem 2005, 280:37349-37359.

73. Falcón C, Carranza F, Martínez FF: Excretory-secretory products (ESP) from Fasciola hepatica induce tolerogenic properties in myeloid dendritic cells. Vet Immunol Immunopathol 2010, 137:36-46.

74. Kar S, Ukil A, Das PK: Cystatin cures visceral leishmaniasis by NF-KBmediated proinflammatory response through co-ordination of TLR/ MyD88 signaling with p105-Tpl2-ERK pathway. Eur J Immunol 2011 41:116-127.
75. Harnett W, Harnett MM: Helminth-derived immunomodulators: can understanding the worm produce the pill? Nat Rev Immunol 2010, 10:278-284.

76. Plevy SE, Targan SR: Future therapeutic approaches for inflammatory bowel diseases. Gastroenterology 2011, 140:1838-1846.

77. Cario E, Brown D, McKee M, Lynch-Devaney K, Gerken G, Podolsky DK: Commensal-associated molecular patterns induce selective toll-like receptor-trafficking from apical membrane to cytoplasmic compartments in polarized intestinal epithelium. Am J Patho 2002, 160:165-173.

78. van Stijn CM, Meyer S, van den Broek M, Bruijns SC, van Kooyk Y, Geyer R, van Die I: Schistosoma mansoni worm glycolipids induce an inflammatory phenotype in human dendritic cells by cooperation of TLR4 and DC-SIGN. Mol Immunol 2010, 7-8:1544-1552.

79. Donnelly S, O'Neill SM, Stack CM, Robinson MW, Turnbull L, Whitchurch C, Dalton JP: Helminth cysteine proteases inhibit TRIF-dependent activation of macrophages via degradation of TLR3. J Biol Chem 2010, 285:3383-3392

80. Lee J, Gonzales-Navajas JM, Raz E: The "polarizing-tolerizing" mechanism of intestinal epithelium: its relevance to colonic homeostasis. Semin Immunopathol 2008, 30:3-9.

81. Ahn DH, Crawley SC, Hokari R, Kato S, Yang SC, Li JD, Kim YS: TNF-alpha activates MUC2 transcription via NF-kappa B but inhibits via JNK activation. Cell Physiol Biochem 2005, 15:29-40.

82. Correale J, Farez M: Helminth antigens modulate immune responses in cells from multiple sclerosis patients through TLR2-dependent mechanisms. J Immunol 2009, 183:5999-6012.

doi:10.1186/1756-3305-4-186

Cite this article as: Sun et al:: Toll-like receptor activation by helminths or helminth products to alleviate inflammatory bowel disease. Parasites \& Vectors $20114: 186$

\section{Submit your next manuscript to BioMed Central and take full advantage of:}

- Convenient online submission

- Thorough peer review

- No space constraints or color figure charges

- Immediate publication on acceptance

- Inclusion in PubMed, CAS, Scopus and Google Scholar

- Research which is freely available for redistribution

Submit your manuscript at www.biomedcentral.com/submit
C) Biomed Central 